fessional development, to balance the influence of industry. ${ }^{10}$ Although support from these quarters also has the potential to introduce bias, the diversification of funding sources has in fact begun: the support of the Ontario Ministry of Health and Long-Term Care and of the Ontario Medical Association for the Guidelines Advisory Committee ${ }^{11}$ is an example, as is the federal government's Primary Health Care Transition Fund ${ }^{12}$ initiative with the Association of Canadian Medical Colleges. This could be just the beginning.

4. Organize dialogue, develop guidelines, give the process legs and teeth. Who will continue the dialogue, and how? Who will develop Canada-wide guidelines and see to their application? Although guidelines do exist at the local level (the University of Toronto's are arguably the most stringent in the country ${ }^{13}$ ) and overall accreditation guidelines are in place, ${ }^{14}$ there is wide variability in their application. Clearly, we need a national body to take on the challenge of containing, examining and regulating the issues for all Canadian health care such as the Committee on Accreditation for Continuing Medical Education (a collaborative accreditation process of the Canadian Medical Association), the Association of Canadian Medical Colleges, the Royal College of Physicians and Surgeons of Canada and the College of Family Physicians of Canada, among other groups.

Are there more steps to take in the process? Of course. But if we want physicians to have the necessary information, skills and confidence to make informed decisions (for example, in choosing between course A and B), and thus to be better able to balance learning needs and patient concerns, these four action items might be a start.

This article has been peer reviewed.

Dr. Davis is Associate Dean, Continuing Education, Faculty of Medicine, University of Toronto.
Competing interests: Dr. Davis has provided advice to and has spoken at events sponsored by pharmaceutical companies. He has adjudicated in one case involving a possible abuse of CME guidelines, and he is the chair of the Ontario Guidelines Advisory Committee. He uses honoraria generated from industry activities to support the Academic Development Fund in Continuing Education at the University of Toronto.

Acknowledgements: The author thanks Sandra Leith and Richard Van Harrison, for their review of the manuscript. Joanne Goldman and Laure Perrier also helped in its completion.

\section{References}

1. Relman AS. Defending professional independence: ACCME's proposed new guidelines for commercial support of CME. FAMA 2003;289:2418-20.

2. Wazana A. Physicians and the pharmaceutical industry. Is a gift ever just a gift? 7AMA 2000;283:373-80.

3. Code of marketing practices. Ottawa: Canada's Research-Based Pharmaceutical Companies; revised Jan 2004. Available: www.canadapharma.org/Industry_Publications /Code/Code_of_marketing-ENJan2004.pdf (accessed 2004 April 6).

4. Society for Academic Continuing Medical Education. Biennial survey. Available: www.sacme.org/Biennial_Survey/default.htm (accessed 2004 April 6).

5. Lexchin J. Interactions between physicians and the pharmaceutical industry: What does the literature say? CMAf 1993;149(10):1401-7.

6. Relman AS, Angell M. America's other drug problem. N Republic 2002;27-41.

7. Coyle SL; Ethics and Human Rights Committee, American College of Physicians-American Society of Internal Medicine. Physician-industry relations. Part 1: individual physicians. Ann Intern Med 2002;136(5):396-402.

8. Coyle SL; Ethics and Human Rights Committee, American College of Physicians-American Society of Internal Medicine. Physician-industry relations. Part 2: organizational issues. Ann Intern Med 2002;136(5):403-6.

9. Steward DE. A proposal to enhance the disclosure of potential conflict of interest for continuing medical education events. Teach Learn Med 2003;15(4):267-9.

10. What's wrong with CME? [editorial] CMA7 2004;170(6):917.

11. Guideline Advisory Committee. Recommended clinical practice guidelines. Available: www.gacguidelines.ca (accessed 2004 April 6).

12. Health Canada. Primary Care Transition Fund. Available: www.hc-sc.gc.ca /phctf-fassp (accessed 2004 April 6).

13. Policy on support of University of Toronto sponsored continuing education activities from commercial sources. Toronto: University of Toronto; 1999. Available: www.library.utoronto.ca/medicine/staff_info/Commercial_Support.pdf (accessed 2004 April 6).

14. Accreditation Council for Continuing Medical Education. Standards for commercial support. Standards to ensure the independence of CME activities. Available: www.accme.org/incoming/174_Standards\%20for\%20Commercial\%20Support _April\%202004.pdf (accessed 2004 April 6).

Correspondence to: Dr. David A. Davis, Continuing Education,

Faculty of Medicine, 650-500 University Ave., Toronto ON

M5G 1V7; fax 416 971-2722; dave.davis@utoronto.ca

\title{
The future sponsorship of CME in Canada: Industry, government, physicians or a blend?
}

\section{Bernard Marlow}

ß See related article page 149

A recent editorial in $C M A 7^{1}$ pointed out that continuing medical education (CME) programs financed by pharmaceutical companies can present information in a biased manner - that, in effect, some of these are thinly disguised efforts to market products. The editorial questioned the roles of professional associations - including the College of Family Physicians of Canada - in providing oversight of CME content offered for educa- tional credit. Certainly, there is evidence that the pharmaceutical industry can influence physician prescribing through marketing and educational efforts..$^{2-5}$ In addition, many "unrestricted grants" from commercial sponsors focus on programs that cover an area of practice related to the donor's products, leaving many "orphan" topics that attract no financial support. Yet the fact remains that the pharmaceutical industry in Canada has been a major con- 
tributor to innovative, ethically conducted, continuing education programs and health education research. At the CACHE (Canadian Association of Continuing Health Education) meetings in 2002 and 2003, of 155 abstracts that passed a rigorous peer-review process and were accepted for presentation, 63 had authors or coauthors who worked for industry.

Because of the obvious bias that can result when a sponsor chooses the topics for $\mathrm{CME}$ and has a hand in writing content, proposals for tightening controls on programs sponsored by industry have been put forward. The US Accreditation Council on Continuing Medical Education - a national agency that accredits CME programs - has floated changes to its guidelines. Under the proposed changes, physicians who have accepted money from the pharmaceutical industry would be banned for life from presenting at accredited CME events. Although others have argued that there are advantages to this proposal, ${ }^{6}$ if it were put into effect it would empty lecterns and podia across the continent. Industry has recruited many of the best of our teachers and researchers for the development and delivery of their sponsored CME programs.

Sponsorship by industry has come under close scrutiny by government, medical organizations, the media and even industry itself. New proposals to regulate $\mathrm{CME}$ could soon become so restrictive as to choke off the financial support provided by industry to assist physicians in attending CME courses. ${ }^{7}$ The costs of $\mathrm{CME}$ are not trivial. Physicians must not only pay for the course and the costs of attending, but must continue to pay office overhead and lose income during their absences. Unlike other professionals, they cannot pass these costs on to their patients in the form of higher fees. If tougher restrictions on financing CME result in reductions (and perhaps even withdrawal) of commercial sponsorship, tuition fees for quality educational offerings will surely increase, adding to the burden on physicians who are trying to maintain their skills.

Some provinces have begun to pay physicians for attending CME programs. This is one solution. A second would be government grants to CME providers to create effective programs at no cost to physicians. A third would be to encourage and create new models whereby unrestricted grants from industry are truly unrestricted.

What are these new models? At the College of Family Physicians of Canada we have separated industry support from CME activities. For example, our Family Medicine Forum receives generous industry support. The CME program, however, is developed entirely by a planning committee with no pharmaceutical representation. Funding is derived from the sale of booths at an adjacent exhibit hall. Attendees have the option of just attending the lectures or of also visiting the companies' booths. Those attending the lectures receive CME credit. In essence, the organizers create a firewall between commercial interests and education, and the registrants benefit from reduced registration fees. There are many examples of pharmaceutical companies working with universities and professional societies to create quality educational programs free from commercial bias. We need to be more vigilant to prevent the few offenders from denigrating all.

The College of Family Physicians of Canada also has a role to play in approving CME courses for credit. Course organizers submit their programs to university CME offices or chapters of the College for review by assigned accreditors. They must submit all materials and answer a series of questions, which includes revealing their sources of commercial support. Once a program is accredited, there is currently no system to audit them as they are being presented. Over the past few months the College has been investigating a system of random audits, including assigned auditors, telephone interviews of attendees and standardized questions concerning commercial bias in post-course evaluations. The College anticipates that the new audit procedures will be implemented as soon as the evaluations are complete. The College of Family Physicians of Canada is in favour of blending these solutions: to pay physicians for lost income, to give government grants to universities and professional associations to create programs, and to continue to support and create cooperative models whereby providers and industry can educate physicians without bias.

Dr. Marlow is Director of CME/CPD, College of Family Physicians of Canada, Mississauga, Ont.

Competing interests: None declared.

\section{References}

1. What's wrong with CME? [editorial]. CMAf 2004;170(6):917.

2. Wolfe SM. Why do American drug companies spend more than $\$ 12$ billion a year pushing drugs? Is it education or promotion? 7 Gen Intern Med 1996;11:637-9.

3. Wazana A. Physicians and the pharmaceutical industry. Is a gift ever just a gift? 7AMA 2000;283:373-80

4. Bowman MA. The impact of drug company funding on the content of continuing medical education. Mobius 1986;6:66-9

5. Bowman MA, Pearle DL. Changes in drug prescribing patterns related to commercial company funding of continuing medical education. 7 Contin Educ Health Prof 1988;8:13-20.

6. Relman AS. Defending professional independence: ACCME's proposed new guidelines for commercial support of CME. FAMA 2003;289(18):2418-20.

7. Van Harrison R. The uncertain future of continuing medical education: commercialism and shifts in funding. F Contin Educ Health Prof 2003;23(4):198-209.

Correspondence to: Dr. Bernard Marlow, College of Family

Physicians of Canada, 2630 Skymark Ave., Mississauga ON L4W 5A4; 905 629-0893; bm@cfpc.ca 